\title{
Guilty or innocent? About the role of choice blindness and own-race bias in eyewitness identifications
}

\section{Faculty of Psychology and Neuroscience}

Supervisor: Anna Sagana

Cohort: 2013

\section{Iris van Sambeek}

Iris van Sambeek is in her third year of the bachelor programme of Psychology and Neuroscience at Maastricht University. Her main research interests are the reliability of eyewitness testimonies, false confessions and memory. Apart from her interest in research, she is also interested in the clinical field of psychology.
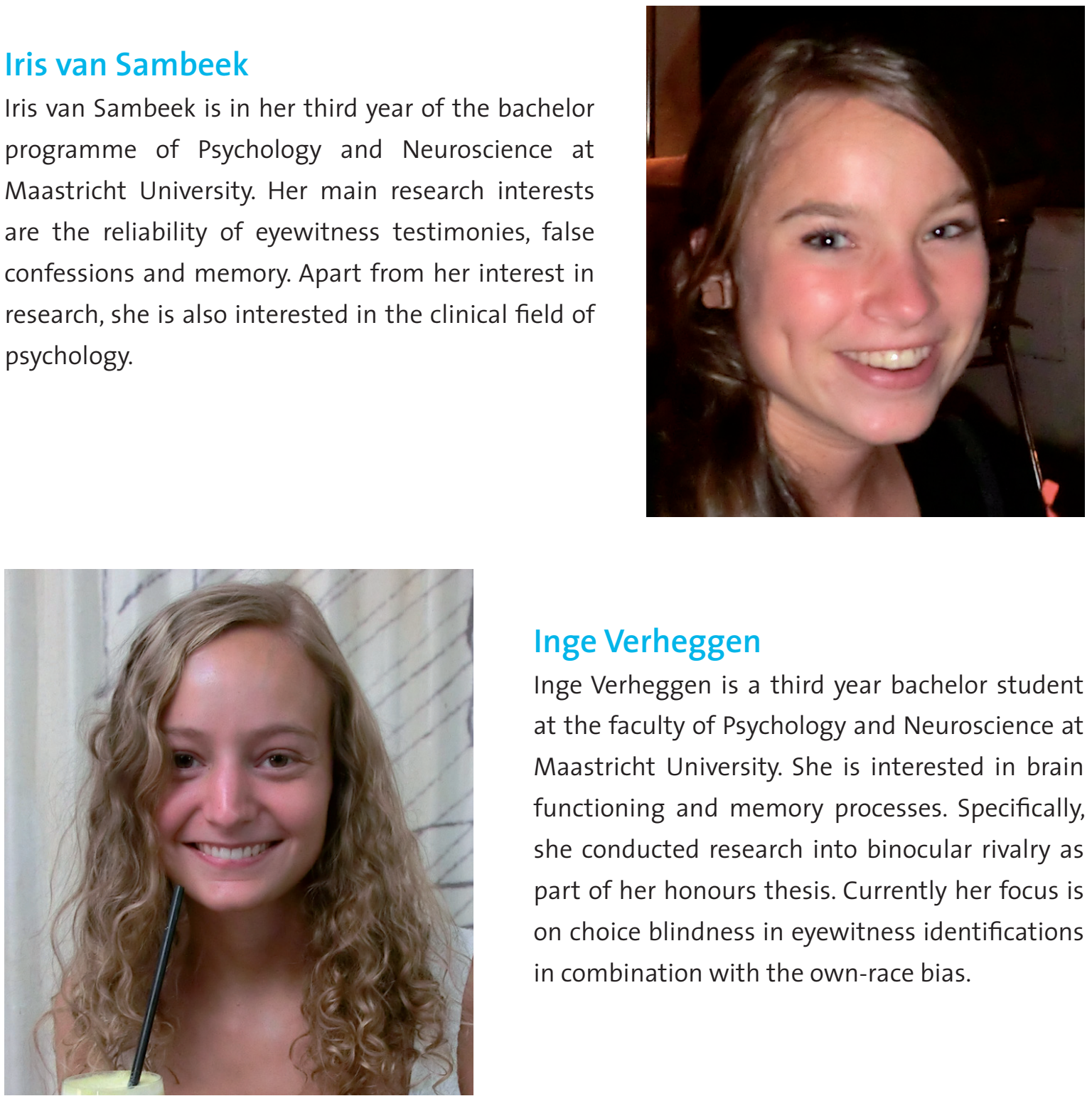

\section{Inge Verheggen}

Inge Verheggen is a third year bachelor student at the faculty of Psychology and Neuroscience at Maastricht University. She is interested in brain functioning and memory processes. Specifically, she conducted research into binocular rivalry as part of her honours thesis. Currently her focus is on choice blindness in eyewitness identifications in combination with the own-race bias. 
Most of us would say that we would notice if the ice-cream seller gave us strawberry icecream, when we actually asked for chocolate. However, several studies indicate that people do not always notice changes in the outcome of their decisions. This phenomenon is called choice blindness and occurs in a wide variety of domains. Apparently, it is even possible that eyewitnesses do not notice that the person they identified from a lineup earlier is not identical with a person presented to them later. If this already occurs in own-race cases, what should we expect if an eyewitness has to identify a person from another race? Due to the own-race bias, people have more difficulty in recognizing faces from another race than from their own race. Do people also have more difficulty in noticing a switch in the outcome of their identification decision when they have to identify other-race faces compared to ownrace faces? The present article, we examine the role of choice blindness and the own-race bias in the performance of eyewitnesses.

\section{Choice blindness}

Making choices is an important aspect of life. In fact, some choices can have a great impact on our future. But what happens if we do not notice changes in the outcome of our own decisions? Would you notice, for example, if the shop-assistant provided you with a blue sweater, when in fact you had selected a green one? And would you provide your friend with reasons for this very choice (that you did not make) when asked? Most people will conclude that this is impossible. However, several studies (Hall, Johansson, Tärning, Sikström, \& Deutgen, 2010; Johansson, Hall, Sikström, \& Olsson, 2005; Sauerland, Sagana, \& Otgaar, 2012) have shown that this phenomenon, named choice blindness, is part of the human mind.

Johansson et al. (2005) conducted one of the studies which demonstrated the existence of choice blindness. Participants had to decide which of two female pictures they thought was more attractive. When participants had made a decision, they were handed the chosen picture and were asked to motivate their choice. However, sometimes their choice was manipulated and as a result participants received the picture they had not initially chosen. Only $13 \%$ of the manipulated choices were detected.

Visual stimuli such as pictures are not the only stimuli that can elicit choice blindness. In a study of Hall et al. (2010), participants tasted two different jams and smelled two different tea samples and indicated which one they preferred. Thereafter, participants 
were asked to taste or smell the preferred jam or tea a second time and to motivate their choice. However, sometimes participants were presented with the non-preferred sample this time. Only $33 \%$ of the manipulated jam trials and $32 \%$ of the tea trials were detected by participants.

As our eyes, nose, and mouth are unable to prevent the effect of choice blindness neither are our ears. Specifically, Sauerland et al. (2012) had participants listen to three pairs of voices. For each pair, they had to indicate which voice sounded either most attractive or most criminal. Immediately after their decision, participants listened to the chosen voice again and matched it with a face. However, during the second trial, the experimenter played the nonchosen voice to the participants during the second listening round. Only $19 \%$ of the participants immediately detected this switch (concurrent detection). Another $10 \%$ of the participants, who did not notice the change concurrently, answered they had noticed the change in voices on a final questionnaire at the end of the experiment (retrospective detection).

Decisions of people seem to be prone to choice blindness in a variety of domains. What does this imply about the decisions that are made by eyewitnesses? Imagine that you have to identify the perpetrator of a crime from a lineup. During the court hearing, a person different from the one you identified appears on the dock - either by mistake or on purpose. Imagine the consequences for the defendant if you do not notice this change in identity and confirm that the person in the courtroom is identical to the perpetrator.

A study of Sagana, Sauerland, and Merckelbach (2013) found that eyewitnesses could indeed be blind for changes in their lineup decisions. Their participants were asked to identify perpetrators from individual photo lineups after they had watched four films each showing a different mock crime. Each mock crime was played by four actors: one perpetrator, one victim and two bystanders. After each film, participants had to identify all four actors from independent 6-person lineups and to indicate how certain they were of each identification on a scale from o to $100 \%$. Two days later, participants came back to the lab. They were asked to imagine that they were now at trial and that the judge had asked them to motivate the four perpetrator identification decisions they had made two days earlier. Additionally, they were again asked to indicate how certain they were of each decision. However, for two of the four perpetrators, participants were presented with a different lineup member than the one they had originally identified. Only $32 \%$ of all the manipulations were detected concurrently and another $29 \%$ of the manipulations were detected retrospectively. 


\section{The own-race bias}

As the study of Sagana et al. (2013) shows, choice blindness is present in eyewitness identifications, which involve the recognition of another person. A different phenomenon that makes recognition of another person more difficult is known as the own-race bias. The own-race bias refers to the fact that people are better at recognizing faces from their own race than from other races (Bothwell, Brigham, \& Malpass, 1989). Meissner and Brigham (2001) analysed data from 39 articles involving nearly 5000 participants and found that overall people displayed a higher proportion of hits (recognizing a familiar face) and a lower proportion of false alarms (mistakenly recognizing an unfamiliar face) when they had to recognize faces from their own race compared to faces from other races. Herzmann, Willenbockel, Tanaka, and Curran (2011) recently found that Caucasian participants displayed less brain activation when looking at own-race faces than when looking at other-race faces, indicating that less brain activation is necessary for memory encoding of own-race faces than of other-race faces.

Hence, during eyewitness identifications the own-race bias increases the chances of a misidentification, which could lead to innocent people being convicted (Wright, Boyd, \& Tredoux, 2003). At the same time, research into choice blindness has shown that eyewitnesses can be blind for their identification decisions when these are secretly manipulated. Now imagine a situation where the choice blindness paradigm is supplemented with a cross-race situation. Will this make it even more difficult for participants to detect a change between the initial choice and a manipulated choice?

\section{Testing the impact of choice blindness and own-race bias on eyewitness performance}

The studies of Sambeek (2013) and Verheggen (2013) examined the combined impact of choice blindness and the own-race bias on eyewitness performance. Their procedure was mostly the same as Sagana et al.'s (2013). However, participants were either black South Africans or white South Africans, while the stimulus film displayed white Europeans. We expected that black Africans would detect less often the manipulations than white Africans due to the own-race bias. Black Africans concurrently detected $5 \%$ of all the manipulations. Another $19 \%$ were detected in retrospect. White Africans detected $13 \%$ of the manipulations concurrently and another $33 \%$ retrospectively (see Figure 1 ). On a descriptive level, these results are consistent with the expectation that black Africans should detect the manipulations less often than white Africans. However, this difference 
was not significant for both concurrent and retrospective detection. The concurrent detection rates in this study were significantly lower than those obtained by Sagana et al. (2013) looking at white Dutch participants (32\%). No significant differences were found for retrospective detection.

While the result that black Africans concurrently detected the manipulations less often than Dutch participants is in line with our expectations, the finding that white Africans did not outperform black Africans is not. In our view, this result could possibly be explained with the difference in environment and interracial contact of the white samples used in the two studies. In a meta-analysis, Meissner and Brigham (2001) found that interracial contact moderates the own-race bias, such that people with low interracial contact have an increased own-race bias compared to people with high interracial contact. White Africans have fewer chances to come in contact with white faces than Dutch participants and therefore they could be less familiar with these faces. In Stellenbosch (South Africa), where the African sample was tested, about $45 \%$ of the population is white and $52 \%$ of the population is black. The remainder is coloured, referring to a heterogeneous ethnic group with a high level of mixed ancestry, or Indian. These are the four main racial groups identified by law in South Africa.

\section{Detection rates}

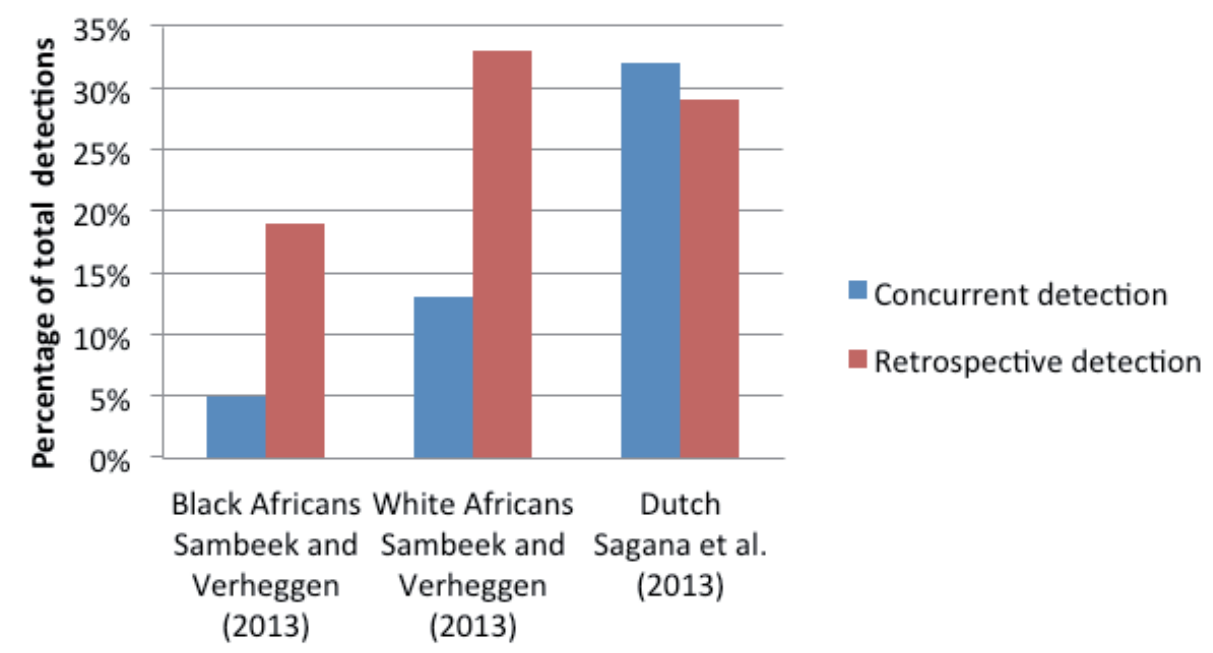

Figure 1: Concurrent and retrospective detection rates of black African, white African and white Dutch participants. 
In terms of identification accuracy, although there was a trend for an own race bias, black Africans were not significantly less accurate (59\%) than white Africans (66\%). However, Dutch participants were accurate at a 90\% rate for the perpetrator lineups, which is significantly higher than the accuracy rate found for black and white Africans. The finding that black Africans are less accurate than the Dutch participants could be a manifestation of the own-race bias. The decreased identification accuracy for white Africans compared to the Dutch participants could be explained by the difference in environment and interracial contact, since white Africans could be less familiar with white faces and are therefore outperformed by Dutch participants. The own-race bias was not evident between black Africans and white Africans, but the own-race bias could be evident across studies, between black Africans and Dutch participants. The finding that the Dutch participants also had significantly higher concurrent detection rates could suggest that the own-race bias moderates choice blindness, but this conclusion has to be treated with caution.

Indeed, other differences between the two studies might be more capable to explain the current results. First, our participants were presented with both target-absent (i.e., suspect was innocent) and target-present lineups and they were given the opportunity to reject the lineups. Sagana et al.'s (2013) Dutch participants, however, were forced to make a choice and only target-present lineups were used. Thus, Sagana et al.'s participants were more likely to make a correct decision, given that they were forced to choose while being presented with a target-present lineup. In contrast, in the current study, participants could falsely choose from target-absent lineups and falsely reject a target-present lineup.

Second, the two samples differed such that Dutch participants were mostly psychology undergraduates who are obliged to participate in research and therefore much more accustomed to do so. At Stellenbosch University (South Africa), however, participation in research is much less common. Therefore, the Dutch participants might have been more at ease and less stressed during their participation.

The finding that the choice blindness rates differed across the two studies only for concurrent, but not retrospective detection, might be explained with cultural differences. A study by Allik and McCrae (2004) examined personality factors in different cultural groups, including black and white South Africans and Dutch participants. Their results indicated that Europeans scored lower on Agreeableness, which in turn is related to compliance, compared to South Africans. Hence, Dutch participants might be less responsive to the demand characteristics of the situation and report more concurrent detections. However, if this were the case, the African sample should have made more additional retrospective detections than the Dutch participants in Sagana et al.'s (2013) study. Specifically, if the African sample did not report as many concurrent detections, because such behavior did not match the demands of the situation, they should have reported these detections retrospectively, when the demands of the situation required them to do so. 


\section{Implications for the legal system}

People often value making their own choices a great deal, but little do they know how likely it is that they will not even notice if their preferred option is replaced by another. Besides contributing to general knowledge about human decision making, research into choice blindness could eventually assist the legal system. The legal system strongly values eyewitness identifications, where a consequence of choice blindness could be the conviction of an innocent person. In the Netherlands, for instance, the police fundamentally assume that an eyewitness tells the truth. The eyewitness first makes a statement at the police station, which can involve providing assistance with the construction of a composite sketch. The eyewitness is often invited back once a suspect has been arrested, and is then presented with a lineup. For cases that are passed on to a judge, the eyewitness is obligated to appear in court. The judge is even allowed to detain eyewitnesses when they refuse to do so, which shows how important eyewitness testimonies are considered to be. In court, the judge can ask further questions about the statement previously made at the police station (Raad voor de Rechtspraak, 2008). Imagine the possibility that the lineup administrator writes down an identification decision different from the one the eyewitness made. The eyewitness would then be presented with a person different from the one identified earlier. Given the findings on choice blindness, it is possible that the eyewitness might not notice this change and hence agree that the person presented in court is identical with the perpetrator and the person selected from the lineup earlier. If eyewitnesses do not even notice that the perpetrator identified from the lineup is replaced with another person, how can their statements be trusted enough in the first place?

More research is necessary to establish whether the increased amount of choice blindness in the African sample can really be attributed to the own-race bias. If this is indeed the case and the own-race bias moderates choice blindness, this poses another problem for the legal system. The legal system should not only take choice blindness and the own-race bias into account, but also the combination between these phenomena, when evaluating eyewitness identifications. Especially in cross-racial eyewitness identifications, the legal system should be careful with considering statements of eyewitnesses as conclusive proof. For choice blindness in cross-racial eyewitness identifications to actually pose a problem for the legal system, two things must happen. Firstly, the eyewitness must be presented with the wrong person in court and secondly, the eyewitness' race must differ from the suspect's race. Admittedly, it seems unlikely for such cases to occur. On the other hand, the police are only human and therefore prone to mistakes. Indeed, Sagana et al. (2013) report about a real case of choice blindness. Here, the actually identified person was to be found in the audience while another person was presented as selected suspect. 
A general issue in lineup administration is that police tend to use procedures with a high level of contact between the lineup administrator and the eyewitness (Steblay, Dysart, Fulero, \& Lindsay, 2001). This has shown to influence eyewitness identification outcomes, with eyewitnesses tending to make decisions consistent with the lineup administrator's expectations (Haw, \& Fisher, 2004). This demonstrates that suboptimal procedures can be in place, even in a structural way. Also, crimes involving people from different races do occur. Even though chances are small, the legal system should take the possibility of these events happening in combination into account, since otherwise the consequences can be severe. Better be too careful than risk the conviction of an innocent person.

\section{Glossary}

Choice blindness: The failure to detect a change in the outcome of a choice when this outcome is secretly changed by someone else

Concurrent detection: An immediate detection of a manipulation of the outcome of a choice

Lineup: A selection of faces, including distractors (who are known to be innocent) and a suspect. This suspect can be innocent (target absent lineup) or guilty (target present lineup). It is the task of the eyewitness to decide if the suspect is present and if yes, to identify the person

Own-race bias: The fact that people are better at recognizing faces from their own race than from other races

Retrospective detection: A detection of a manipulation during a later stage of the experiment than on the moment of the manipulation of the outcome of a choice 


\section{References}

Allik, J., \& McCrae, R. R. (2004). Toward a geography of personality traits: Patterns of profiles across 36 cultures. Journal of Cross-Cultural Psychology, 35, 13-28. doi:10.1177/0022022103260382

Bothwell, R. K., Brigham, J. C., \& Malpass, R. S. (1989). Cross-racial identification. Personality and Social Psychology Bulletin, 15, 19-25. doi:10.1177/0146167289151002

Hall, L., Johansson, P., Tärning, B., Sikström, S., \& Deutgen, T. (2010). Magic at the marketplace: Choice blindness for the taste of jam and the smell of tea. Cognition, 117, 54-61. doi:10.1016/j. cognition.2010.06.010

Haw, R. M., \& Fisher, R. P. (2004). Effects of administrator-witness contact on eyewitness identification accuracy. Journal of Applied Psychology, 89, 1106-1112. doi:10.1037/00219010.89.6.1106

Herzmann, G., Willenbockel, V., Tanaka, J. W., \& Curran, T. (2011). The neural correlates of memory encoding and recognition for own-race and other-race faces. Neuropsychologia, 49, 3103-3115. doi:10.1016/j.neuropsychologia.2011.07.019

Johansson, P., Hall, L., Sikström, S., \& Olsson, A. (2005). Failure to detect mismatches between intention and outcome in a simple decision task.Science,310, 116-119.doi:10.1126/science.1111709

Meissner, A., \& Brigham, J. C. (2001). Thirty years of investigating the own-race bias in memory for faces: A meta-analytic review. Psychology, Public Policy, and Law, 7, 3-35. doi:10.1037//10768971.7.1.3

Raad voor de Rechtspraak. (2008). U bent getuige in een strafproces. [Brochure] Den Haag: Raad voor de Rechtspraak.

Sagana, A., Sauerland, M., \& Merckelbach, H. (2013). “This is the person you selected”: About being blind for one's own eyewitness identification decision. Manuscript submitted for publication.

Sambeek, I. (2013). The role of race, choice and accuracy in the blindness for one's own identification decision (Unpublished bachelor's thesis). Maastricht University, Maastricht, The Netherlands.

Sauerland, M., Sagana, A., \& Otgaar, H. (2012). Theoretical and legal issues related to choice blindness for voices. Legal \& Criminological Psychology, 48, 1-11. doi:10.1111/j.20448333.2012.02049.x

Steblay, N., Dysart, J., Fulero, S., \& Lindsay, R. C. L. (2001). Eyewitness accuracy rates in sequential and simultaneous lineup presentations: A meta-analytic review. Law and Human Behavior, 25, 459-473. doi:10.1023/A:1012888715007

Verheggen, I. C. M. (2013). Choice blindness for own and other race eyewitness identifications: Associations to post-decision confidence (Unpublished bachelor's thesis). Maastricht University, Maastricht, The Netherlands.

Wright, D. B., Boyd, C. E., \& Tredoux, C. G. (2003). Inter-racial contact and own-race bias for face recognition in South Africa and England. Applied Cognitive Psychology, 17, 365-373. doi:10.1002/ acp. 898 